DOI: $10.1002 /$

Article type: Communication

\title{
Improved Efficiency in Inverted Perovskite Solar Cells Employing Novel Diarylamino- Substituted Molecule as PEDOT:PSS Replacement
}

Abdulrahman El Labban, Hu. Chen, Mindaugas Kirkus, Jeremy Barbe, Silvano Del Gobbo, Marios Neophytou, Iain Mcculloch, Jessica Eid

Dr. A. El Labban, Dr. H. Chen, Dr. M. Kirkus, Dr. J. Barbe, Dr. S. Del Gobbo, Dr. M.

Neophytou, Prof. I. Mcculloch, Dr. J. Eid

Solar and Photovoltaics Engineering Research Center (SPERC)

Division of Physical Sciences and Engineering

King Abdullah University of Science and Technology

Thuwal 23955-6900, Saudi Arabia

E-mail: Jessica.Eid@kaust.edu.sa

Keywords: perovskites solar cells, inverted planar structure, PEDOT:PSS replacement

We report on the replacement of poly(3,4-ethylenedioxythiophene):polystyrenesulfonate (PEDOT:PSS) commonly used as hole transport layer in inverted perovskite solar cell structures, with two small organic molecules, which are the novel 6-difluoro$N^{1}, N^{1}, N^{2}, N^{2}, N^{4}, N^{4}, N^{5}, N^{5}$-octakis(4-methoxyphenyl)benzene-1,2,4,5-tetraamine (DFTAB) and 4,4',4",4"'-(ethene-1,1,2,2-tetrayl)tetrakis( $N, N$-bis(4-methoxyphenyl)aniline) $\quad$ (TAE). Solar cells using $\mathrm{CH}_{3} \mathrm{NH}_{3} \mathrm{PbI}_{3}$ as photoactive layer and DFTAB as hole transport layer showed improved power conversion efficiency exceeding $12 \%$, open-circuit voltage $\left(\mathrm{V}_{\mathrm{oc}}\right)$ higher than $1 \mathrm{~V}$ and fill factor as high as $69 \%$. These performances exceed the efficiency of our control PEDOT:PSS-based devices. The simple synthesis, low temperature processing and stability of the presented compounds make them particularly interesting for future up-scaled mass production.

Perovskite-based solar cells (PSCs) have achieved remarkably high power conversion efficiencies in a short lapse of time, ${ }^{[1-3]}$ approaching well-established inorganic thin-film technologies such as $\mathrm{CuIn}_{(1-\mathrm{x})} \mathrm{Ga}_{\mathrm{x}}(\mathrm{S}, \mathrm{Se})$ and CdTe. PSCs with two different architectures have 
been developed; First, the conventional structure comprising of a bottom inorganic mesoporous or planar metal oxide electron transport layer (ETL), processed at high temperatures $\left(500^{\circ} \mathrm{C}\right)$, and Spiro-OMeTAD $(2,2,7,7$-tetrakis $(N, N$-di-p-methoxyphenylamine)9,9-spirobifluorene) used as hole transport layer (HTL) ${ }^{[4-9]}$ on top of the photoactive perovskite layer. In contrast, the inverted device architecture consists of a perovskite layer sandwiched between two organic charge transport layers, poly $(3,4-$ ethylenedioxythiophene):polystyrenesulfonate (PEDOT:PSS) and [6,6]-phenyl-C ${ }_{61}$-butyric acid methyl ester (PCBM) as hole and electron transport materials, respectively. The low temperature processing of inverted devices $\left(<100^{\circ} \mathrm{C}\right)^{[10-13]}$ along with the possibility to cast the materials on flexible substrates, holds great potential for low-cost and large-scale solar cell manufacturing. However, the main limitation is the poor chemical stability of PEDOT:PSS due to its acidity and insufficient electron-blocking properties ${ }^{[14-16]}$, which limits achievable power conversion efficiency. Thus, there is considerable motivation to replace PEDOT:PSS in inverted perovskite devices with more stable dopant-free hole transport layers, which are optically transparent in the abundant regions of the solar spectrum. In particular, these HTMs should have destabilized LUMO energy levels for enhanced electron-blocking properties, should be readily synthetically scalable, soluble in a range of low temperature process compatible solvents, and have the required hole transport properties. Therefore, inorganic HTLs such as $\mathrm{NiO}_{\mathrm{X}}$ and $\mathrm{CuSCN}$ were recently suggested to replace PEDOT:PSS, achieving PCEs of $7.2 \%$ and $16.6 \%$, respectively. ${ }^{[14,17-22]}$.

In this work, we report the application of solution processable organic diarylamino-substituted molecule semiconductors based on tetrakis( $N, N$-bis(4-methoxyphenyl)aniline) attached on the two different rigid middle cores, namely 6-difluoro- $N^{1}, N^{1}, N^{2}, N^{2}, N^{4}, N^{4}, N^{5}, N^{5}$-octakis(4methoxyphenyl)benzene-1,2,4,5-tetraamine (DFTAB), and 4,4',4",4'"-(ethene-1,1,2,2tetrayl)tetrakis( $N, N$-bis(4-methoxyphenyl)aniline) (TAE) as alternative hole-transport materials to PEDOT:PSS in inverted planar perovskite solar cells. Previous work showed that 


\section{WILEY-VCH}

TAE can be used as efficient and robust HTM as Spiro-OMeTAD replacement in PSCs with conventional structure, reaching power conversion efficiency as high as $11 \%{ }^{[23]}$. The synthesis of these molecules is relatively simple and cheap. They exhibit high transparency in the range of the perovskite's optical absorption, chemical $\mathrm{pH}$ neutrality and sufficiently high hole mobilities $>10^{-5} \mathrm{~cm}^{2} \mathrm{~V}^{-1} \mathrm{~s}^{-1}$ compared to PEDOT:PSS $\left(10^{-4} \mathrm{~cm}^{2} \mathrm{~V}^{-1} \mathrm{~s}^{-1}\right)$.

Triarylamines represent a class of organic materials showing excellent transport properties, morphological and thermal stability and are consequently widely used as hole-transporters in

OLEDs. ${ }^{[24,25]}$ Usually, this type of materials contains a rigid planar middle core with different peripheral triarylamine groups, which allows for tuning of their optoelectronic properties by changing the substituents on the peripheral groups. In this work, we chose 1,4-diflurobenzene and 1,1,2,2-tetraphenylethene as the central cores with four $N, N$-bis(4-methoxyphenyl)aniline peripheral groups as illustrated in Scheme 1. Both target compounds were easily synthesized on the gram scale in less than two steps from cheap commercially available precursors without using palladium catalysts.

Detailed synthetic procedures and full chemical characterization are provided in the SI. Complete structural characterization of the corresponding intermediates was accomplished by using standard spectroscopic techniques such as ${ }^{1} \mathrm{H}$ NMR, ${ }^{13} \mathrm{C}$ NMR, HRMS and MALDITOF (Figure S1). The thermal properties were investigated by thermal gravimetric analysis (TGA) and differential scanning calorimetry (DSC). The data are shown in Figure S2, S3 and S4.

PSC devices were processed at temperature below $100^{\circ} \mathrm{C}$. This low-temperature solution process approach enables the use of flexible substrates, another possibility for cheap upscaling in future commercialization. The device architecture is schematically depicted in Figure 1a. It consists of a $\mathrm{CH}_{3} \mathrm{NH}_{3} \mathrm{PbI}_{3}$ perovskite absorber layer sandwiched between p-type DFTAB or TAE and n-type PCBM transport layers deposited by spin-coating. The bottom and top electrodes are indium-doped tin oxide (ITO) and silver, respectively. A cross section 


\section{WILEY-VCH}

SEM picture of the device with DFTAB as ETL is shown in Figure 1b. Due to its reduced thickness, the DFTAB HTL is almost undistinguishable from the perovskite layer and appears as a bright line on top of ITO. The thickness of the HTLs was determined by profilometry to be approximately $20 \mathrm{~nm}$. SEM cross-section in Figure S13 shows that the very thin HTL is uniform and entirely covers the ITO without any visible pin holes.

The ionization potentials (IPs) of PEDOT:PSS, DFTAB, TAE and $\mathrm{CH}_{3} \mathrm{NH}_{3} \mathrm{PbI}_{3}$ were determined by photoelectron spectroscopy in air (PESA). The experimental data are shown in the SI (Figure S11) and the obtained energy level values are depicted in Figure 2. The IP of DFTAB $(-5.2 \mathrm{eV})$ is sligthly higher than that of ETMA $(-4.9 \mathrm{eV})$. However, since both values lie well between that of the perovskite and the work function of ITO, no transport limitations arising from injection/extraction are expected.

Corresponding electron affinity (EA) values of TAE and DFTAB were determined via the sum of the IP and the optical band-gap $\left(E_{\text {opt }}\right)$ estimated by UV-Vis absorption spectroscopy, yelding - $2.2 \mathrm{eV}$ and $-2.1 \mathrm{eV}$, respectively. The high LUMO levels ensures the required electron blocking function, thus preventing electron transfer from the absorbing perovskite directly to the ITO anode. On the contrary, PEDOT:PSS possesses intraband states due to PSS dopant $^{[26,27]}$ resulting in a non-negligible electron flow towards the anode and eventually recombination at the perovskite/ITO interface.

Thin-film optical absorption and photoluminescence spectra of DFTAB and TAE are shown in Figure 3 in comparison to PEDOT:PSS. TAE has an absorption onset at $470 \mathrm{~nm}$ (optical gap $\left(E_{\mathrm{opt}}=2.7 \mathrm{eV}\right)$, while the DFTAB one shows an onset at $405 \mathrm{~nm}\left(E_{\mathrm{opt}}=3.1 \mathrm{eV}\right)$. Therefore DFTAB is more transparent to incoming visible light reaching the perovskite absorber. The photoluminescence emission spectrum has a maximum at $540 \mathrm{~nm}$ for TAE and $465 \mathrm{~nm}$ for DFTAB. These values agree with the onset of absorption spectra considering stokes shift between absorption and emission in a semiconductor. 


\section{WILEY-VCH}

Space charge limited current (SCLC) measurements were used to determine the hole mobilities, which are $2.4 \times 10^{-5} \mathrm{~cm}^{2} \mathrm{~V}^{-1} \mathrm{~s}^{-1}$ for DFTAB, $1.6 \times 10^{-5} \mathrm{~cm}^{2} \mathrm{~V}^{-1} \mathrm{~s}^{-1}$ for TAE and $\sim 10^{-4} \mathrm{~cm}^{2} \mathrm{~V}^{-1} \mathrm{~s}^{-1}$ for PEDOT:PSS (Figure S14 in SI).

Perovskite solar cells were fabricated on ITO-coated glass substrates. DFTAB and TAE were spin-coated from chlorobenzene solution, whereas PEDOT:PSS was spin-coated as purchased (acqueous solution). In order to optimize the HTL layer deposition, various thicknesses were investigated (Figure $\mathrm{S} 9$ ). The $\mathrm{CH}_{3} \mathrm{NH}_{3} \mathrm{PbI}_{3}$ absorber was successively introduced using a onestep fast deposition-crystallization method. After annealing at $100^{\circ} \mathrm{C}$, the PCBM layer was spin-casted from chlorobenzene (CB) followed by evaporation of a $100 \mathrm{~nm}$ silver top electrode (see details in SI).

The optimized thicknesses for the different layers in the device were found to be approximately $20 \mathrm{~nm}$ for the HTL, $170 \mathrm{~nm}$ for the $\mathrm{CH}_{3} \mathrm{NH}_{3} \mathrm{PbI}_{3}$ and $50 \mathrm{~nm}$ for the PCBM. The typical active area of the cells was $0.1 \mathrm{~cm}^{2}$. Devices were tested under AM1.5G solar illumination $\left(100 \mathrm{~mW} / \mathrm{cm}^{2}\right)$. As for PEDOT:PSS, very good device reproducibility was achieved with both small molecules (Figure S8). The two compounds yield similar or even higher device performance even though no dopants or additives were added. In contrast, PEDOT requires acidic PSS dopants to gain the required hole transport properties. The same holds true for Spiro-OMeTAD, which is casted from solution containing additives and dopant compounds.

Figure 4a shows current-voltage $(J-V)$ characteristics of PSCs fabricated with the different HTL layers. Devices with DFTAB yield the highest efficiencies of up to $12.4 \%$ and opencircuit voltage $0.15 \mathrm{~V}$ higher than that of PEDOT:PSS devices. The photovoltaic parameters averaged from 16 devices are summarized in table 1 . The statistical PV parameters illustrated in Figure S8 show small dispersion over the devices, indicating satisfying reproducibility of the process. A study of the stability of PSCs over time has also been carried out (Figure S10). It can be observed that the two molecules TAE and DFTAB improve the stability of the cells 
compared to PEDOT:PSS. After $360 \mathrm{~h}$ aging, the PCE is lowered by only 5\% and $10 \%$ for TAE and DFTAB respectively. In the case of PEDOT:PSS, the PCE is lowered by $17 \%$ after the same period of time in inert atmosphere, mainly due to $\mathrm{V}_{\text {oc }}$ and FF decrease. As shown in Figure S7, there is only small hysteresis between reverse and forward scans for the different HTLs, with slight improvement for DFTAB and TAE-based devices.

For TAE and DFTAB, the trend of $\mathrm{V}_{\mathrm{oc}}$ is in line with the values of measured HOMO levels. However, according to Figure 2 we would have expected an intermediate $\mathrm{V}_{\mathrm{oc}}$ value for PEDOT:PSS devices. This can be explained by the presence of polaronic or bipolaronic bands in PEDOT:PSS that lie just above the valence band level and work as hole acceptors, slightly lowering the $\mathrm{V}_{\mathrm{oc}}{ }^{28,29}$.

The $\mathrm{J}_{\mathrm{sc}}$ of both DFTAB- and TAE-based devices remained lower than that of PEDOT:PSS devices (cf. Table 1). This can also be observed in the EQE spectra in Figure 4b. The EQEs of DFTAB- and TAE-based devices are unexpectedely lower than the EQE of PEDOT:PSS device for $\lambda>600 \mathrm{~nm}$, although PEDOT:PSS has higher absorption in the near IR (Figure 3). This behavior was already observed in another report but not explained ${ }^{30}$. We believe that this is ascribable to electric field fluctuations in the light absorber layer due to small variations in the perovskite film thickness on the different HTLs. Indeed, the EQE is strongly thickness dependent for $\lambda>500 \mathrm{~nm}$ (low finesse thin film interference regime) ${ }^{31}$. Therefore, even small variations of the thickness are able to cause large oscillations of EQE and thus $\mathrm{J}_{\mathrm{SC}}$. On the contrary, in the low wavelength range $(300 \mathrm{~nm}-400 \mathrm{~nm})$ PEDOT:PSS-based devices show a reduced EQE compared to DFTAB and TAE-based devices. This can be attributed to higher recombination at the $\mathrm{PEDOT}: \mathrm{PSS} / \mathrm{CH}_{3} \mathrm{NH}_{3} \mathrm{PbI}_{3}$ interface since higher energy light is immediately absorbed by the first layers of the photoactive layer $\left(\mathrm{CH}_{3} \mathrm{NH}_{3} \mathrm{PbI}_{3}\right)$. In all cases, the EQE spectra are not affected by the optical absorption of the HTMs given their very low thickness $(20 \mathrm{~nm})$. The $\mathrm{J}_{\mathrm{SC}}$ obtained from the integral of the EQE spectra matches perfectly the values obtained from $\mathrm{J}-\mathrm{V}$ curves. 


\section{WILEY-VCH}

In conclusion, we have reported two organic hole transport small molecules, the novel 6difluoro- $N^{1}, N^{1}, N^{2}, N^{2}, N^{4}, N^{4}, N^{5}, N^{5}$-octakis(4-methoxyphenyl)benzene-1,2,4,5-tetraamine (DFTAB), and 4,4',4",4"'-(ethene-1,1,2,2-tetrayl)tetrakis( $N, N$-bis(4-methoxyphenyl)aniline) (TAE), which are easily processable at low temperature and from low cost starting materials. These molecules are potential candidates as cheap, stable HTL materials for the replacement of the commonly used PEDOT:PSS in inverted planar $\mathrm{CH}_{3} \mathrm{NH}_{3} \mathrm{PbI}_{3}$ solar cells. When integrated into a perovskite-based device, DFTAB HTL achieved $12.4 \%$ efficiency with a $\mathrm{V}_{\mathrm{oc}}$ reaching $1.07 \mathrm{~V}$. 


\section{WILEY-VCH}

Supporting Information

Supporting Information is available from the Wiley Online Library or from the author.

Acknowledgements

The authors acknowledge Dr. Max Tietze for useful discussions and comments.

Received: ((will be filled in by the editorial staff))

Revised: ((will be filled in by the editorial staff))

Published online: ((will be filled in by the editorial staff))

\section{References}

[1] H. S. Kim; C. R. Lee; J. H. Im; K. B. Lee; T. Moehl; A. Marchioro; S. J. Moon; R. Humphry-Baker; J. H. Yum; J. E. Moser; M. Gratzel; N. G. Park Sci. Rep. 2012, 2, 591. [2] J. Burschka; N. Pellet; S.-J. Moon; R. Humphry-Baker; P. Gao; M. K. Nazeeruddin; M. Grätzel Nature 2013, 499, 316.

[3] N. J. Jeon; J. H. Noh; Y. C. Kim; W. S. Yang; S. Ryu; S. I. Seok Nat Mater 2014, 13, 897.

[4] D. Liu; T. L. Kelly Nat. Photon. 2014, 8, 133.

[5] M. Liu; M. B. Johnston; H. J. Snaith Nature 2013, 501, 395.

[6] L. Yang; U. B. Cappel; E. L. Unger; M. Karlsson; K. M. Karlsson; E. Gabrielsson; L. C. Sun; G. Boschloo; A. Hagfeldt; E. M. J. Johansson Phys. Chem. Chem. Phys. 2012, 14, 779. [7] N. Cai; S. J. Moon; L. Cevey-Ha; T. Moehl; R. Humphry-Baker; P. Wang; S. M. Zakeeruddin; M. Gratzel Nano Lett. 2011, 11, 1452.

[8] S. J. Moon; Y. Itzhaik; J. H. Yum; S. M. Zakeeruddin; G. Hodes; M. Gratzel J. Phys. Chem. Lett. 2010, 1, 1524.

[9] S. Fantacci; F. De Angelis; M. K. Nazeeruddin; M. Gratzel J. Phys. Chem. C 2011, 115, 23126.

[10] C.-H. Chiang; Z.-L. Tseng; C.-G. Wu J. Mater. Chem. A 2014, 2, 15897.

[11] Z. Xiao; C. Bi; Y. Shao; Q. Dong; Q. Wang; Y. Yuan; C. Wang; Y. Gao; J. Huang Energy Environ. Sci. 2014, 7, 2619.

[12] M. Qian; M. Li; X. B. Shi; H. Ma; Z. K. Wang; L. S. Liao J. Mater. Chem. A 2015, 3, 13533.

[13] W. H. Ren; Z. P. Zheng; Y. Z. Luo; W. Chen; C. J. Niu; K. N. Zhao; M. Y. Yan; L. Zhang; J. S. Meng; L. Q. Mai J. Mater. Chem. A 2015, 3, 19850.

[14] M. D. Irwin; D. B. Buchholz; A. W. Hains; R. P. H. Chang; T. J. Marks Proceedings of the National Academy of Sciences 2008, 105, 2783.

[15] M. Jørgensen; K. Norrman; F. C. Krebs Sol. Energy Mater. Sol. Cells 2008, 92, 686.

[16] K. Norrman; M. V. Madsen; S. A. Gevorgyan; F. C. Krebs J. Am. Chem. Soc. 2010, 132, 16883.

[17] S. Ye; W. Sun; Y. Li; W. Yan; H. Peng; Z. Bian; Z. Liu; C. Huang Nano Lett. 2015, 15, 3723.

[18] P. Pattanasattayavong; N. Yaacobi-Gross; K. Zhao; G. O. N. Ndjawa; J. H. Li; F. Yan; B. C. O'Regan; A. Amassian; T. D. Anthopoulos Adv. Mater. 2013, 25, 1504.

[19] S. Agarwal; M. Seetharaman; N. K. Kumawat; A. S. Subbiah; S. K. Sarkar; D. Kabra; M. A. G. Namboothiry; P. R. Nair J Phys Chem Lett 2014, 5, 4115.

[20] J. Du; X. X. Meng; K. Zhao; Y. Li; X. H. Zhong J. Mater. Chem. A 2015, 3, 17091.

[21] C.-G. Wu; C.-H. Chiang; Z.-L. Tseng; M. K. Nazeeruddin; A. Hagfeldt; M. Grätzel

Energy Environ. Sci. 2015, 8, 2725. 


\section{WILEY-VCH}

[22] P. Qin; S. Tanaka; S. Ito; N. Tetreault; K. Manabe; H. Nishino; M. K. Nazeeruddin; M. Grätzel Nat. comm. 2014, 5.

[23] L. Cabau; I. Garcia-Benito; A. Molina-Ontoria; N. F. Montcada; N. Martin; A. VidalFerran; E. Palomares Chem. Comm. 2015, 51, 13980.

[24] Y. Kuwabara; H. Ogawa; H. Inada; N. Noma; Y. Shirota Adv. Mater. 1994, 6, 677.

[25] Z. Jiang; T. Ye; C. Yang; D. Yang; M. Zhu; C. Zhong; J. Qin; D. Ma Chem. Mater. 2010, 23,771 .

[26] A. Lenz; H. Kariis; A. Pohl; P. Persson; L. Ojamae Chem Phys 2011, 384, 44.

[27] O. Bubnova; Z. U. Khan; H. Wang; S. Braun; D. R. Evans; M. Fabretto; P. Hojati-Talemi; D. Dagnelund; J. B. Arlin; Y. H. Geerts; S. Desbief; D. W. Breiby; J. W. Andreasen; R. Lazzaroni; W. M. M. Chen; I. Zozoulenko; M. Fahlman; P. J. Murphy; M. Berggren; X. Crispin Nat Mater 2014, 13, 662.

[28] O. Bubnova; Z. U. Khan; H. Wang; S. Braun; D. R. Evans; M. Fabretto; P. Hojati-Talemi; D. Dagnelund; J.-B. Arlin; Y. H. Geerts Nat Mater 2014, 13, 190.

[29] A. Lenz; H. Kariis; A. Pohl; P. Persson; L. Ojamäe Chem Phys 2011, 384, 44.

[30] K. Zhao; R. Munir; B. Yan; Y. Yang; T. Kim; A. Amassian J. Mater. Chem. A 2015, 3, 20554.

[31] Q. Lin; A. Armin; R. C. R. Nagiri; P. L. Burn; P. Meredith Nat. Photon. 2014.

[32] C. Alemán; E. Armelin; J. I. Iribarren; F. Liesa; M. Laso; J. Casanovas Synth. met. 2005, 149, 151. 


\section{WILEY-VCH}

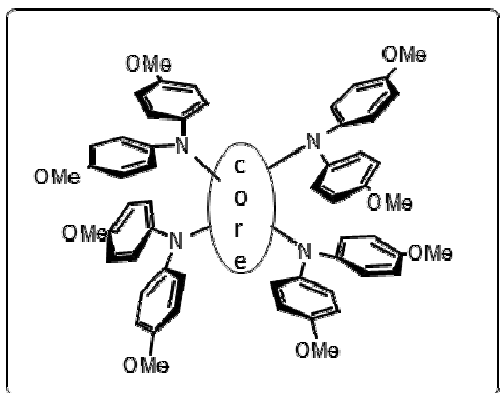

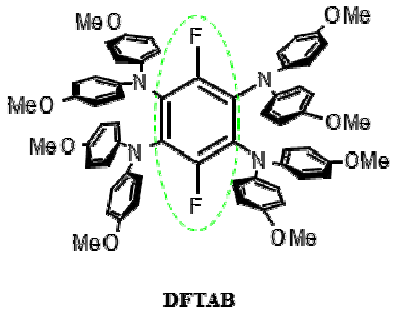

Core $\theta_{1}=1,4$-diflurobenzene

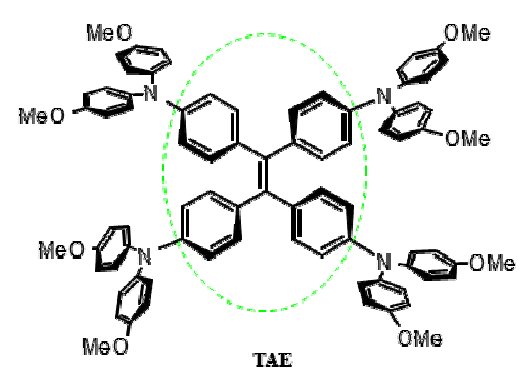

Core $2=1,1,2,2$-tetraphenylethene

Scheme 1. Molecular structures of DFTAB and TAE.
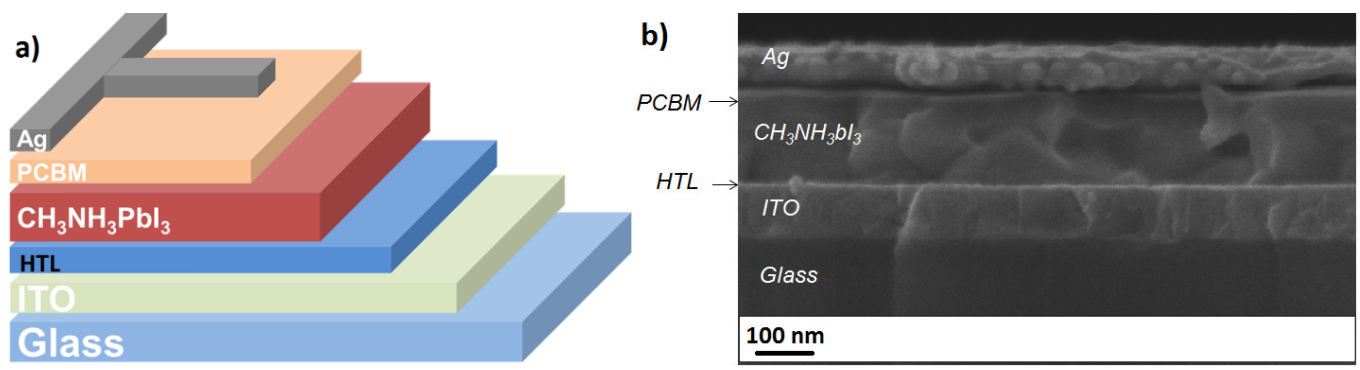

Figure 1. (a) Solar cell architecture schematic and (b) SEM cross-section of the inverted device. 


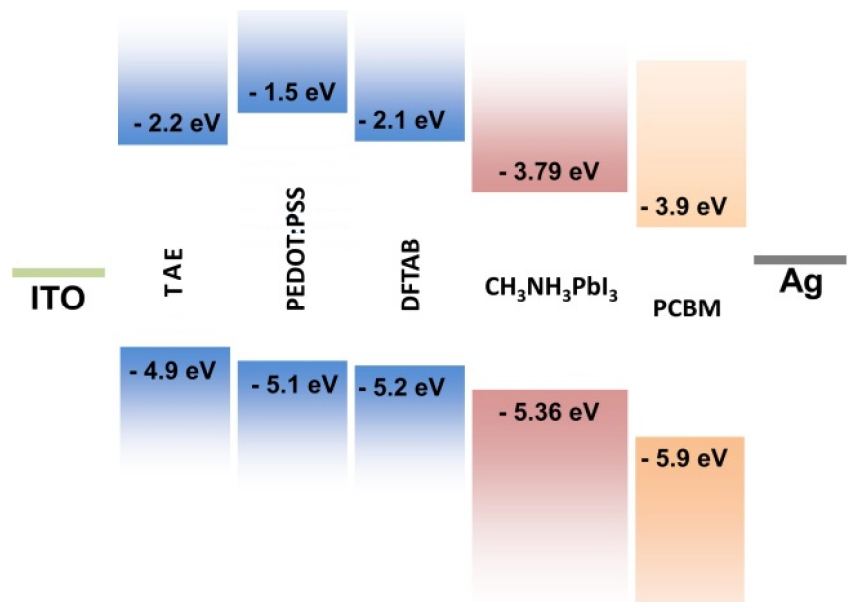

Figure 2. Energy level diagram of each layer in the device including the different HTLs (DFTAB, TAE and PEDOT:PSS). LUMO level of PEDOT:PSS was derived from reference. $^{[26,32]}$
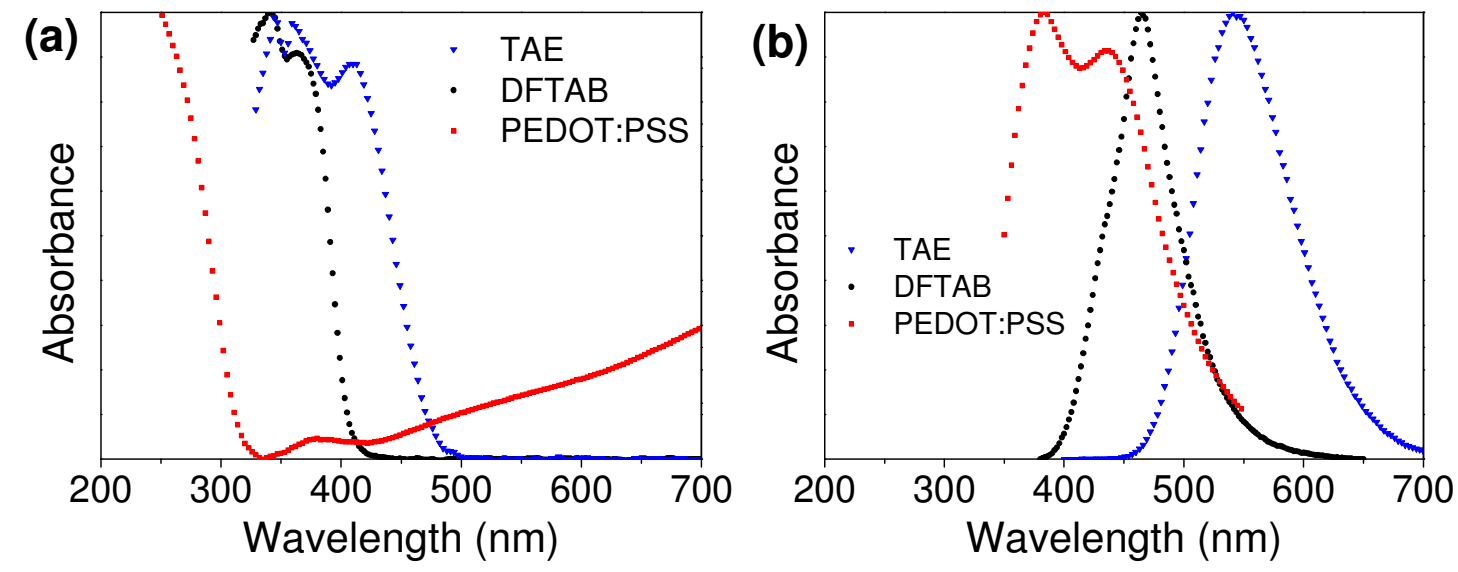

Figure 3. a) Thin film absorbance and b) solution photoluminescence emission spectra of DFTAB, TAE and PEDOT:PSS measured at room temperature. The absorption and PL spectra were normalized to unit. 
WILEY-VCH

(a) 2

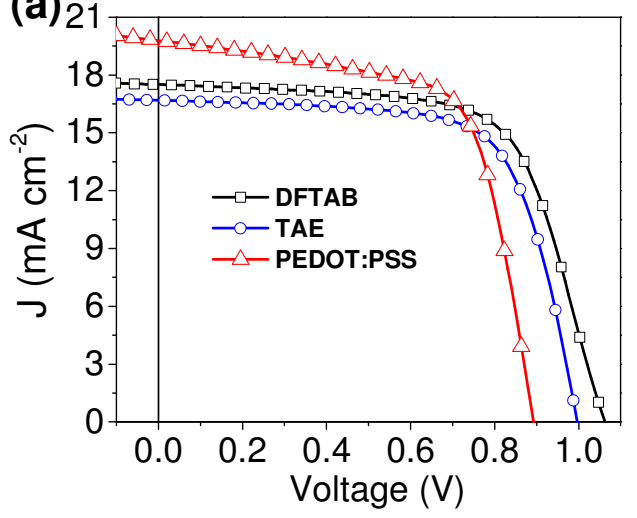

(b)

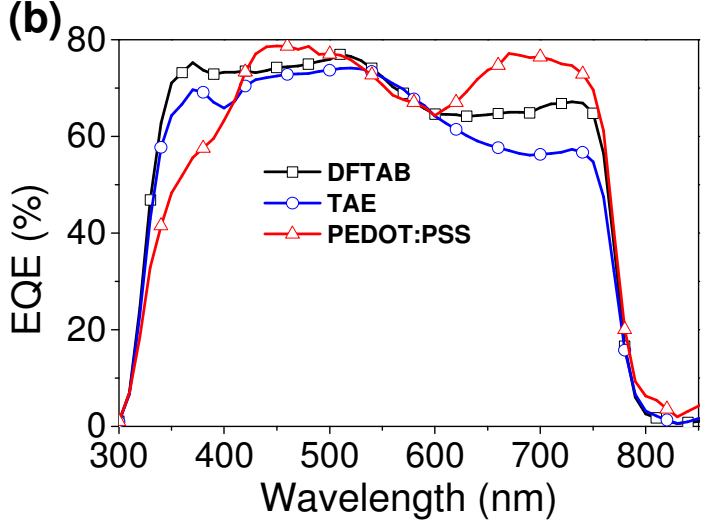

Figure 4. (a) Characteristic $J$ - $V$ curves of best solar cells (under AM1.5G solar illumination) and (b) EQE spectra of devices fabricated with DFTAB, TAE and PEDOT:PSS as HTL with optimized thicknesses.

Table 1. Photovoltaic performance of optimized $\mathrm{CH}_{3} \mathrm{NH}_{3} \mathrm{PbI}_{3}$ solar cells fabricated with different HTLs.

$\begin{array}{cccccc} & J_{\mathrm{sc}} & V_{\text {oc }} & \text { FF } & \text { Avg. PCE } & \text { Max. PCE } \\ \text { HTM } & {\left[\mathrm{mA} / \mathrm{cm}^{2}\right]} & {[\mathrm{V}]} & {[\%]} & {[\%]} & {[\%]} \\ \text { DFTAB } & 17.5 & 1.07 & 69 & 11.8 & 12.4 \\ \text { TAE } & 16.7 & 1.00 & 66 & 11.0 & 11.5 \\ \text { PEDOT:PSS } & 19.7 & 0.90 & 66 & 11.1 & 11.7\end{array}$




\section{WILEY-VCH}

\section{The table of contents}

An approach to fabricate a high-efficiency inverted planar perovskites solar cells using solution-processed organic small molecules hole transporting layer (HTL). Devices using $\mathrm{CH}_{3} \mathrm{NH}_{3} \mathrm{PbI}_{3}$ as photoactive layer and $\mathrm{PC}_{60} \mathrm{BM}$ as electron transport layer showed power conversion efficiencies exceeding $12 \%$ and open-circuit voltages $\left(\mathrm{V}_{0 \mathrm{C}}\right)$ higher than $1 \mathrm{~V}$.

Kewords: perovskites solar cells, inverted planar structure, PEDOT:PSS replacement

Abdulrahman El Labban, Hu. Chen, Mindaugas Kirkus, Jeremy Barbe, Silvano Del Gobbo, Marios Neophytou, Iain Mcculloch, Jessica Eid

\section{Improved Efficiency in Inverted Perovskite Solar Cells Employing Novel Diarylamino- Substituted Molecule as PEDOT:PSS Replacement}

ToC figure ((Please choose one size: $55 \mathrm{~mm}$ broad $\times 50 \mathrm{~mm}$ high or $110 \mathrm{~mm}$ broad $\times 20 \mathrm{~mm}$ high.

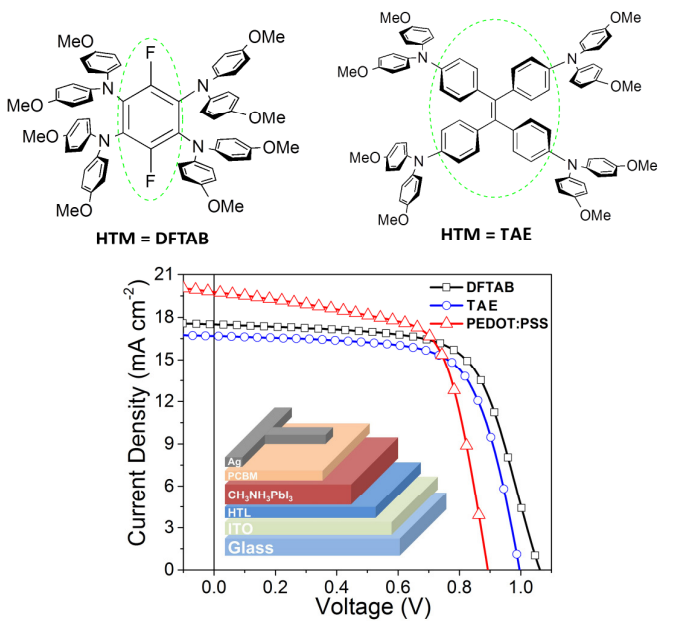




\section{Supporting Information}

\section{Improved Efficiency in Inverted Perovskite Solar Cells Employing Novel Diarylamino- Substituted Molecule as PEDOT:PSS Replacement}

Abdulrahman El Labban, Hu Chen, Mindaugas Kirkus, Jeremy Barbe, Silvano Del Gobbo, Marios Neophytou, Iain Mcculloch, Jessica Eid

\section{General experimental details for synthetic part}

Methods and materials: All reagents from commercial sources were used without further purification. Solvents were dried and purified using standard techniques. All compounds were characterized by ${ }^{1} \mathrm{H}$ NMR $(600 \mathrm{MHz}),{ }^{13} \mathrm{C}$ NMR $(151 \mathrm{MHz})$ on a Bruker Avance III Ultrashielded 600 Plus instrument and at room temperature. High-resolution mass spectrometry (HRMS) data was recorded using a Thermo Scientific - LTQ Velos Orbitrap MS in positive atmospheric pressure photoionization (+APPI) mode. UV-Vis spectra were recorded in a Varian Cary 100 spectrophotometer. Thermogravimetric analysis (TGA) was performed under $\mathrm{N}_{2}$ using Bruker TGA-IR TG209F1 with a ramp of $10{ }^{\circ} \mathrm{C} / \mathrm{min}$. Differential Scanning Calorimetry (DSC) was run on DSC-204F1-phoenix.

\section{Synthetic details and characterization}

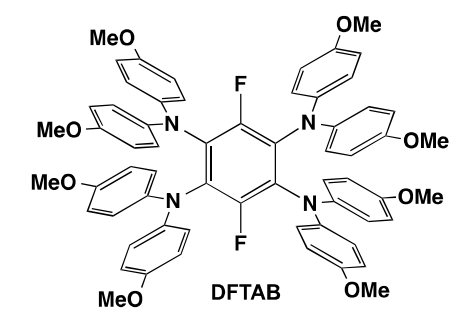

Scheme S1. 3,6-Difluoro- $N^{1}, N^{1}, N^{2}, N^{2}, N^{4}, N^{4}, N^{5}, N^{5}$-octakis(4-methoxyphenyl)benzene-1,2,4,5tetraamine (DFTAB)

To a stirred solution of $\mathrm{NaH}(60 \%$ in mineral oil) $(0.86 \mathrm{~g}, 21.5 \mathrm{mmol})$ in $15 \mathrm{ml}$ dry DMF at 0 ${ }^{\circ} \mathrm{C}$, bis(4-methoxyphenyl)amine $(2.65 \mathrm{~g}, 11.56 \mathrm{mmol})$ was added in one portion. The mixture 
was slowly warmed up to room temperature and stirred for 30 min under inert atmosphere, then perflurobenzene $(0.5 \mathrm{~g}, 2.69 \mathrm{mmol})$ was added slowly. The mixture was stirred at room temperature for two hours and then warmed up to $60{ }^{\circ} \mathrm{C}$ for another two hours. After that, the temperature was increased to $90{ }^{\circ} \mathrm{C}$ and the mixture was stirred overnight. After cooling to room temperature, the reaction was quenched slowly by saturated $\mathrm{NH}_{4} \mathrm{Cl}$ solution $(50 \mathrm{~mL})$ extracted with DCM $(100 \mathrm{~mL} \times 3)$. The organic phase was washed with water, dried with $\mathrm{Na}_{2} \mathrm{SO}_{4}$ and evaporated to dryness. The residue was recrystallized from acetone/dichloromethane as white solid (Yield:72\%). ${ }^{1}$ H NMR: (600 MHz, d6-DMSO) $\delta$ 6.66-6.67 (d, J = 9.0 Hz, 16H), 6.60-6.62 (d, J = 9.0 Hz, 16H), $3.62(\mathrm{~s}, 24 \mathrm{H}) .{ }^{13}$ C NMR: $(151$ $\left.\mathrm{MHz}, \mathrm{CD}_{2} \mathrm{Cl}_{2}\right) \delta 155.73(\mathrm{~d}, \mathrm{~J}=252.2 \mathrm{~Hz}, 156.56,154.89), 155.04,140.11,131.32,122.18$, 113.92, 55.37. HRMS: found: 1023.4108 , calcd. for $\mathrm{C}_{62} \mathrm{H}_{56} \mathrm{~F}_{2} \mathrm{~N}_{4} \mathrm{O}_{8}\left([\mathrm{M}+\mathrm{H}]^{+}\right): 1023.4144$.

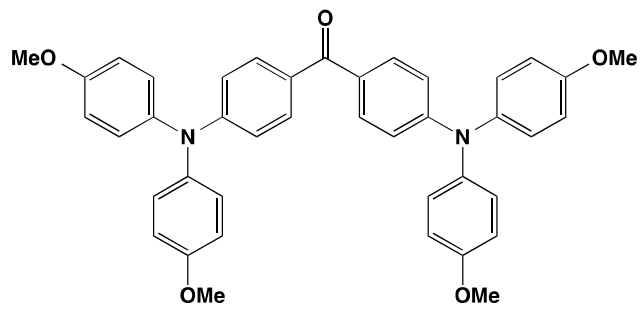

Scheme S2. Bis(4-(bis(4-methoxyphenyl)amino)phenyl)methanone (1)

The mixture of 4,4'-diaminobenzophenone $(2.0 \mathrm{~g}, 9.42 \mathrm{mmol})$, 4-iodoanisole $(17.64 \mathrm{~g}$, $75.38 \mathrm{mmol})$, potassium carbonate $(15.62 \mathrm{~g}, 113.07 \mathrm{mmol})$, copper $(3.7 \mathrm{~g} .56 .53 \mathrm{mmol})$ and 18 crown-6 (124mg, 0.47mmol) in dry $o$-DCB $(15 \mathrm{~mL})$ was refluxed for $16 \mathrm{~h}$. After cooling to room temperature, the reaction mixture was filtered, the remaining solids were washed with DCM and the filtrate was concentrated in vacuum. The residue was purified by flash column chromatography (silica gel) eluting first with n-hexane and finally with the mixture of DCM:n-hexane (50:50 V/V) to give a yellow solid. (Yield:78\%). ${ }^{1} \mathbf{H}$ NMR: $(600 \mathrm{MHz}$, $\left.\mathrm{CDCl}_{3}\right) \delta 6.66-6.67(\mathrm{~d}, \mathrm{~J}=9.0 \mathrm{~Hz}, 16 \mathrm{H}), 6.60-6.62(\mathrm{~d}, \mathrm{~J}=9.0 \mathrm{~Hz}, 16 \mathrm{H}), 3.62(\mathrm{~s}, 24 \mathrm{H}) .{ }^{13} \mathrm{C}$ 
NMR: $\left(151 \mathrm{MHz}, \mathrm{CDCl}_{3}\right) \delta$ 155.73(d, $\left.\mathrm{J}=252.2 \mathrm{~Hz}, 156.56,154.89\right), 155.04,140.11,131.32$, 122.18, 113.92, 55.37. HRMS: found: 1023.4108 , calcd. for $\mathrm{C}_{41} \mathrm{H}_{36} \mathrm{~N}_{2} \mathrm{O}_{5}\left([\mathrm{M}+\mathrm{H}]^{+}\right): 637.748$.

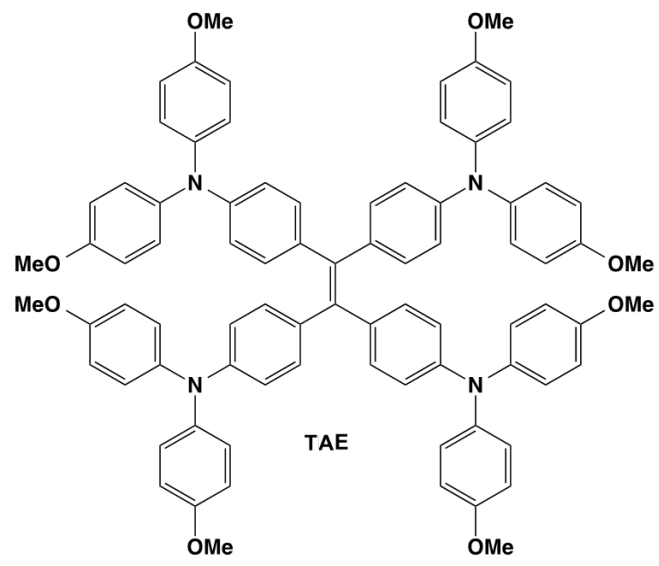

Scheme S3. 4,4',4",4"'-(Ethene-1,1,2,2-tetrayl)tetrakis( $N, N$-bis(4-methoxyphenyl)aniline) (TAE)

To a suspension of zinc powder $(1.23 \mathrm{~g}, 18.84 \mathrm{mmol})$ in $40 \mathrm{~mL}$ of dry THF at $-10{ }^{\circ} \mathrm{C}, \mathrm{TICl}_{4}$ $(1.03 \mathrm{~mL}, 9.42 \mathrm{mmol})$ was added drop-wise keeping the reaction temperature below $-5{ }^{\circ} \mathrm{C}$. The mixture was slowly warmed up to room temperature and stirred for $30 \mathrm{~min}$ and then refluxed for $1 \mathrm{~h}$. The resulting dark solution was warmed to room temperature and a solution of (1) (3.0g, 4.7mmol) in dry THF was added slowly. The reaction mixture was refluxed for $5 \mathrm{~h}$ cooled to the room temperature and quenched by addition of cold saturated $\mathrm{K}_{2} \mathrm{CO}_{3}$ solution $(100 \mathrm{~mL})$, extracted with DCM $(100 \mathrm{~mL} \times 3)$. The organic phase was washed with water, dried with $\mathrm{Na}_{2} \mathrm{SO}_{4}$ and evaporated to dryness. The residue was recrystallized from cold ethanol twice to give a bright yellow solid (Yield:85\%). ${ }^{1} \mathbf{H}$ NMR: $\left(500 \mathrm{MHz}, \mathrm{CD}_{2} \mathrm{Cl}_{2}\right) \delta 7.01$ $(\mathrm{d}, \mathrm{J}=8.9 \mathrm{~Hz}, 16 \mathrm{H}), 6.87(\mathrm{~s}, 8 \mathrm{H}), 6.85-6.78(\mathrm{~m}, 16 \mathrm{H}), 6.69(\mathrm{~d}, \mathrm{~J}=8.7 \mathrm{~Hz}, 8 \mathrm{H}), 3.77(\mathrm{~s}$, $24 \mathrm{H})$

${ }^{13}$ C NMR: $\left(126 \mathrm{MHz}, \mathrm{CD}_{2} \mathrm{Cl}_{2}\right) \delta 155.35,146.30,140.59,136.45,131.67,125.91,119.21$, 114.11, 54.99. MALDI-TOF-MS: m/z 1240.60 (100\%), 1241.61 (90), 1242.62 (40), 1243.63 (10). 
WILEY-VCH

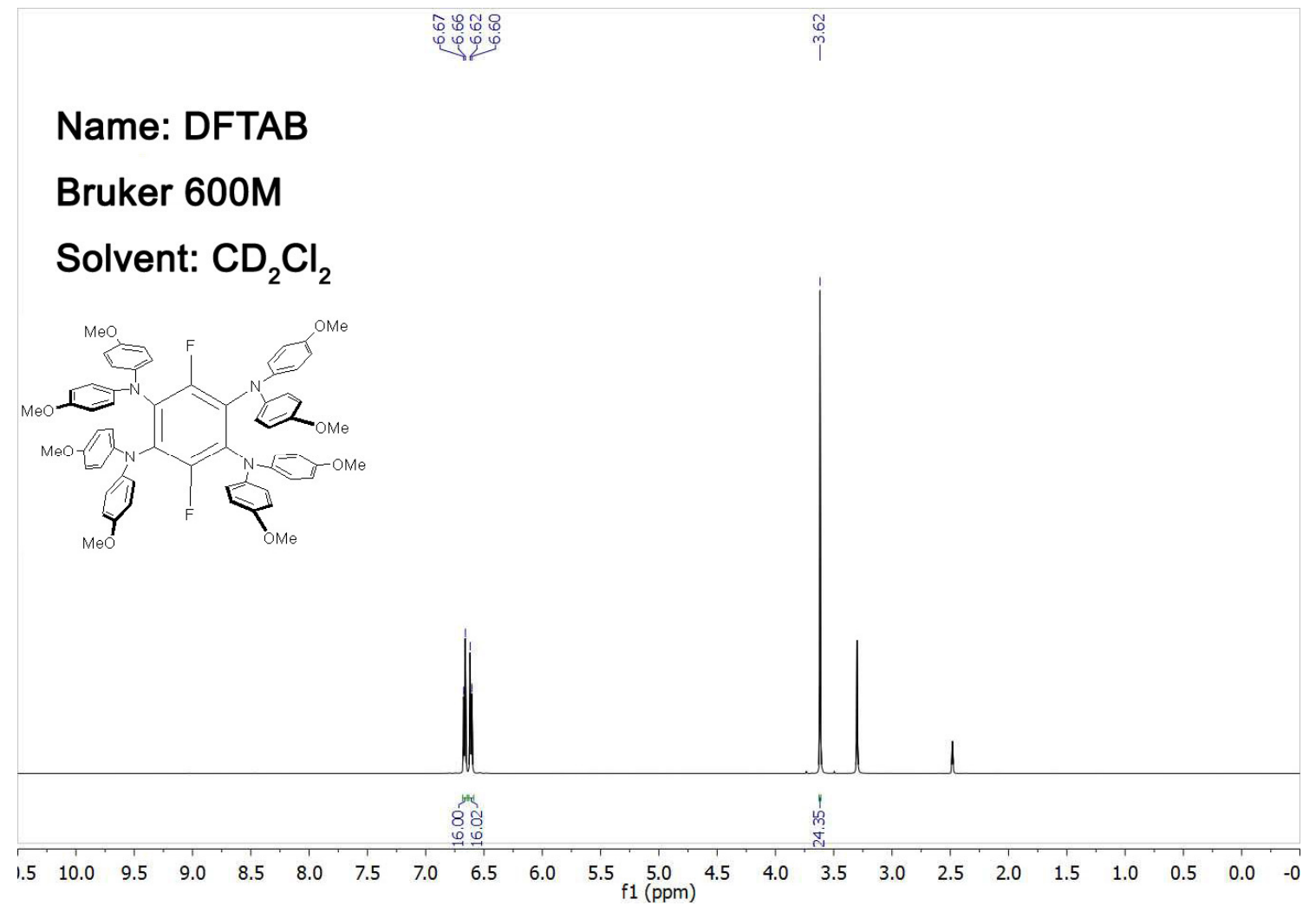

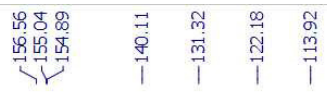

Name: DFTAB

\section{Bruker 600M}

Solvent: $\mathrm{CD}_{2} \mathrm{Cl}_{2}$

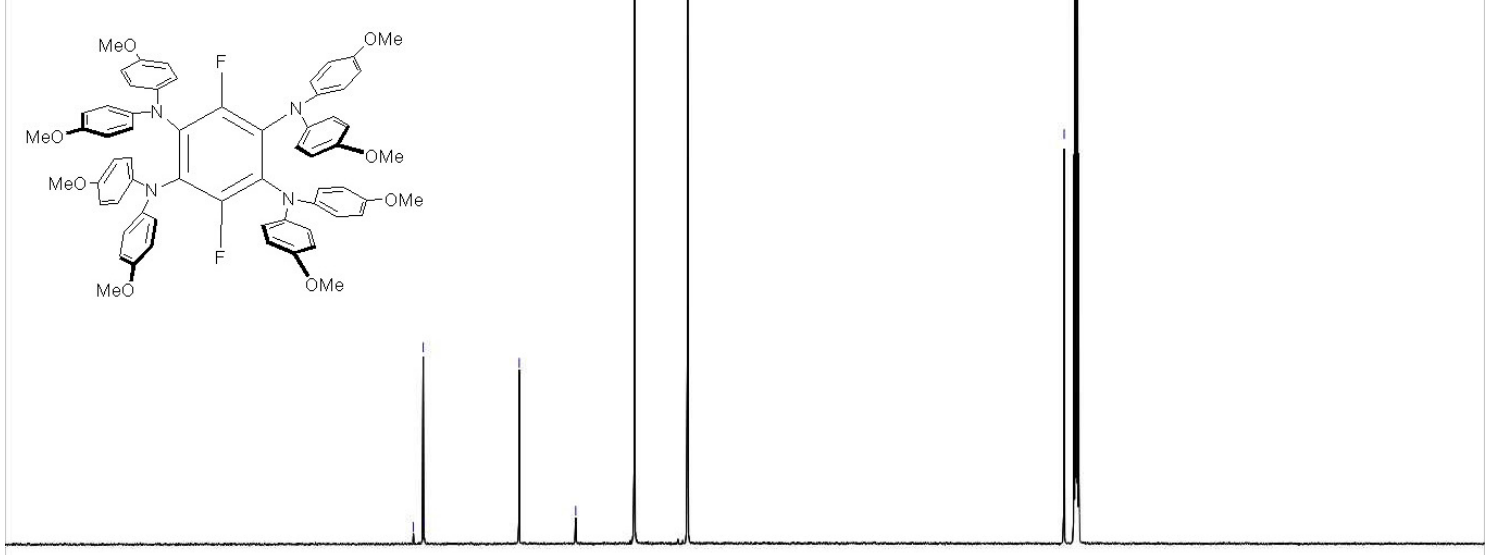

\begin{tabular}{llllllllllllllllllllllllllll}
\hline 20 & 210 & 200 & 190 & 180 & 170 & 160 & 150 & 140 & 130 & 120 & 110 & 100 & 90 & 80 & 70 & 60 & 50 & 40 & 30 & 20 & 10 & 0 & -1
\end{tabular} 
WILEY-VCH

\section{Name: TAE}

\section{Bruker 500M}

Solvent: $\mathrm{CD}_{2} \mathrm{Cl}_{2}$

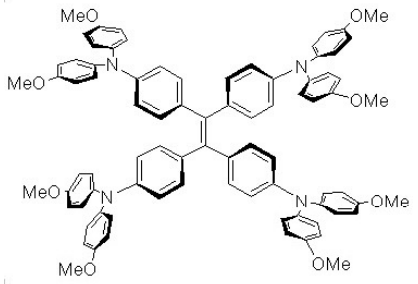
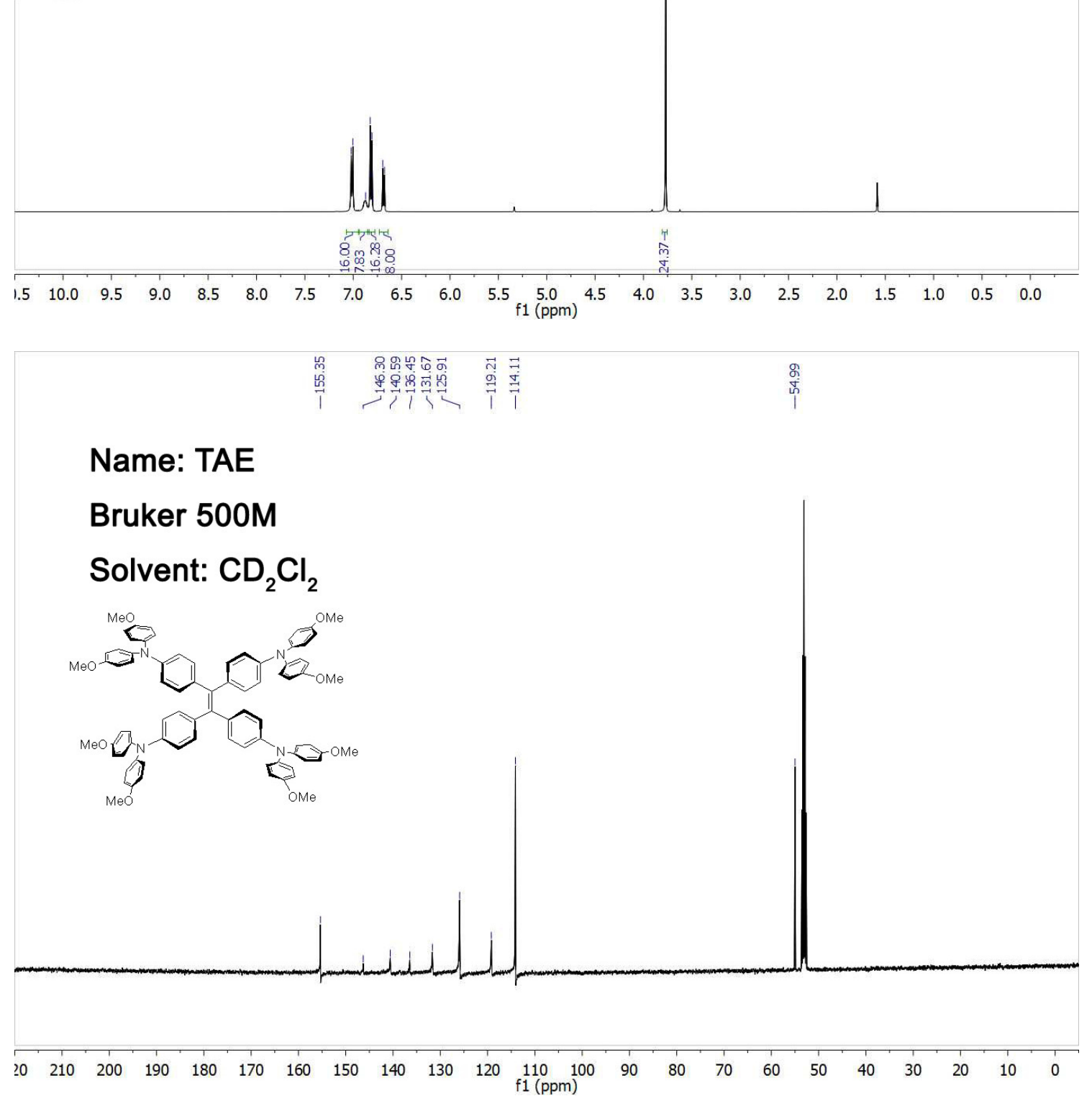

Figure S1. ${ }^{1} \mathrm{H}$ NMR and ${ }^{13} \mathrm{CNMR}$ of DFTAB and TAE 
WILEY-VCH

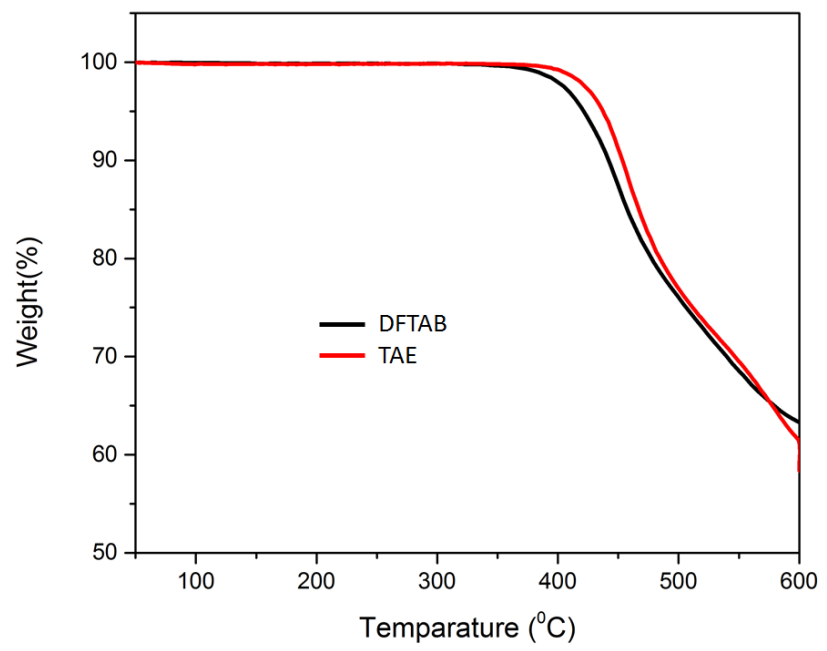

Figure S2. Thermogravimetrical analysis (TGA) curves of DFTAB and TAE at scan rate of $10^{\circ} \mathrm{C} \cdot \mathrm{min}^{-1}$.

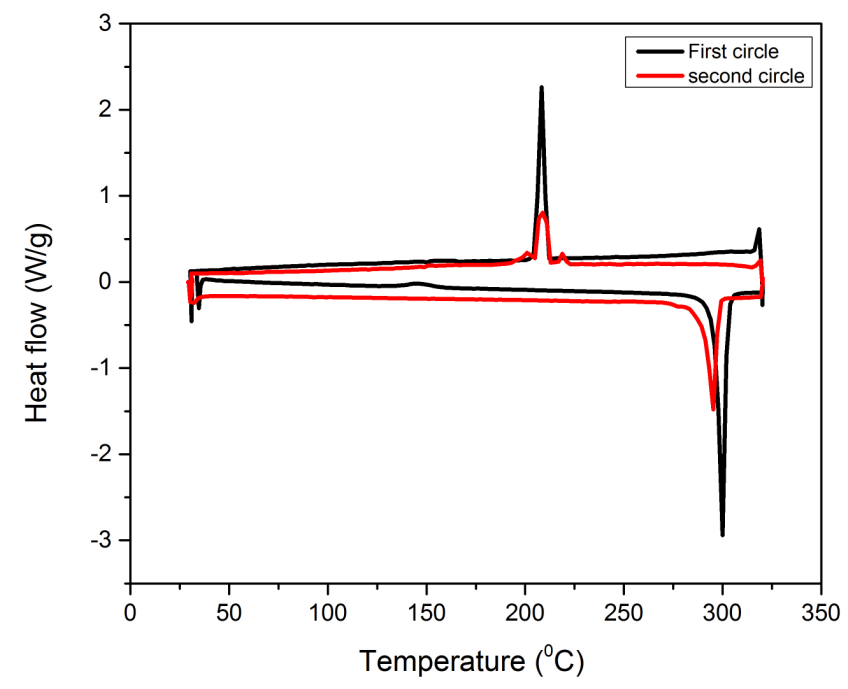

Figure S3. Differential scanning calorimetry curves of DFTAB. 


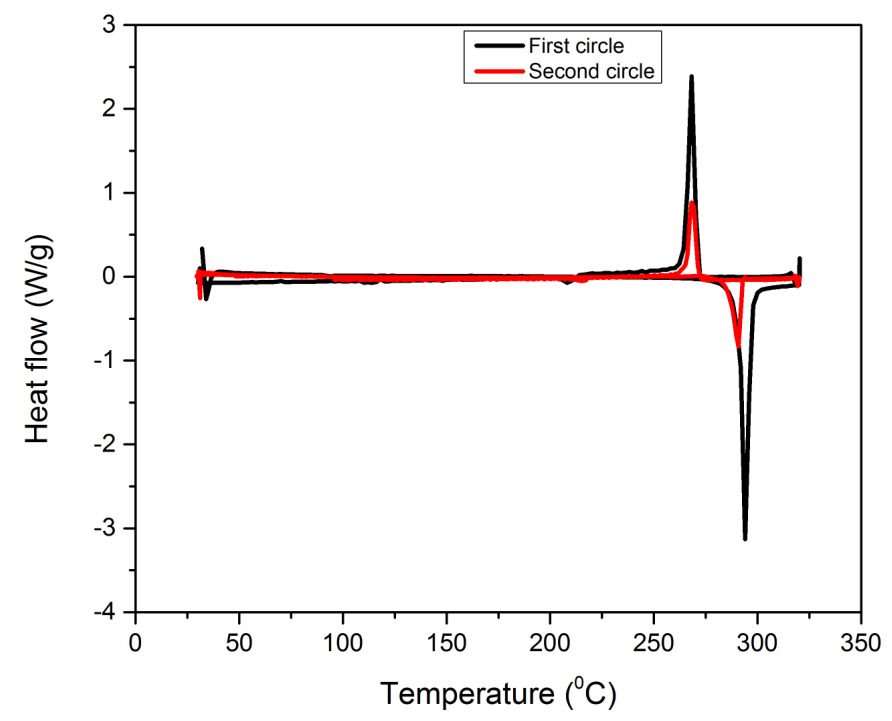

Figure S4. Differential scanning calorimetry curves of TAE.

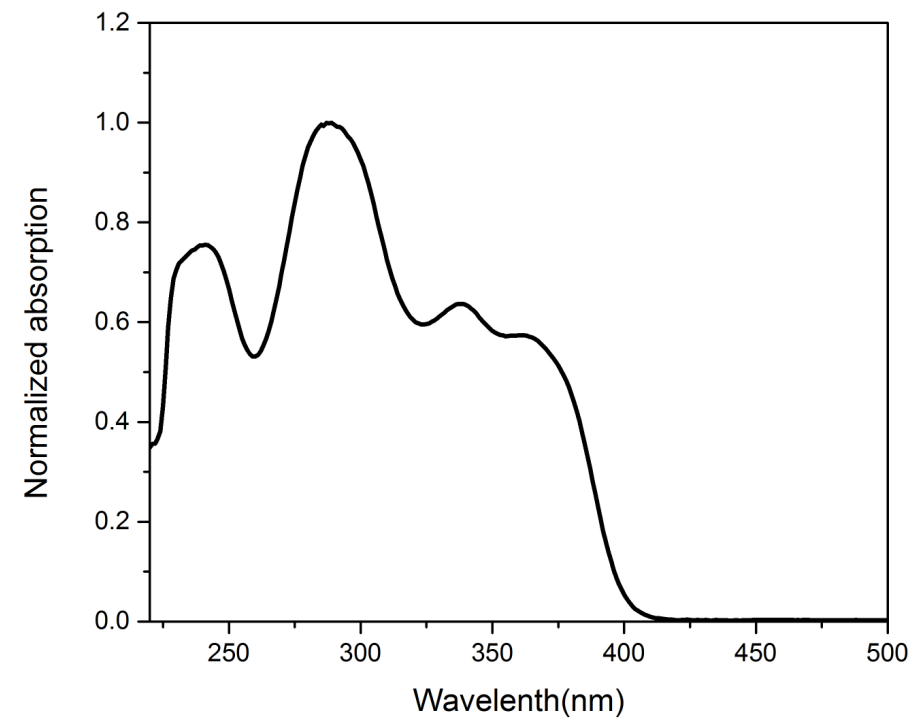

Figure S5. Absorption spectrum of DFTAB in $\mathrm{CH}_{2} \mathrm{Cl}_{2}$ solution. 


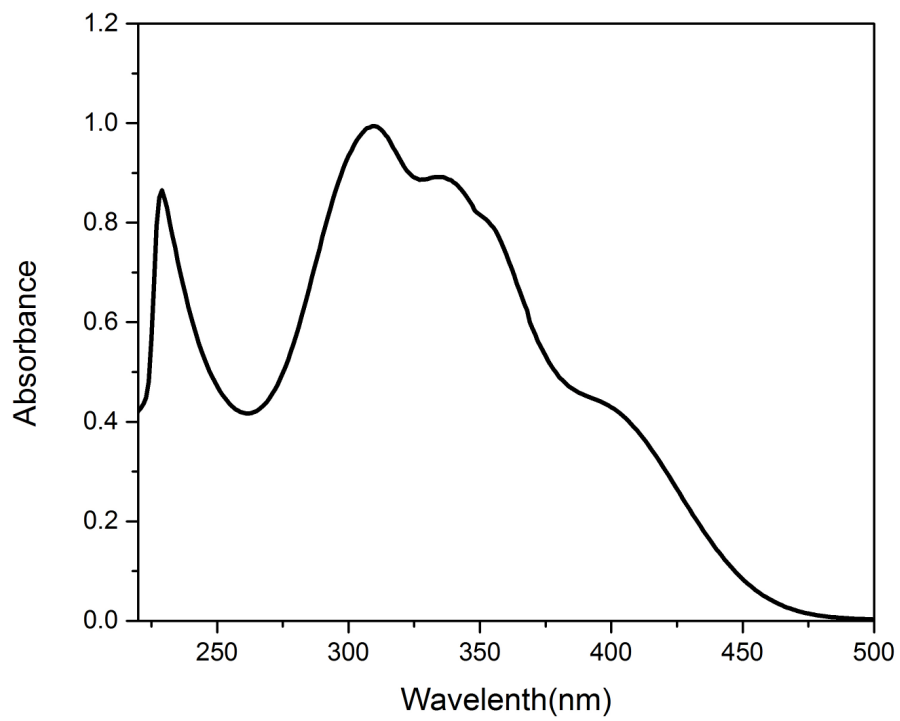

Figure S6. Absorption spectrum of TAE in $\mathrm{CH}_{2} \mathrm{Cl}_{2}$ solution.

\section{Device preparation}

The $\mathrm{CH}_{3} \mathrm{NH}_{3} \mathrm{PbI}_{3}$ Perovskite solar cells were prepared on glass substrates with tin-doped indium oxide (ITO, $15 \Omega \mathrm{sq}^{-1}$ ) patterned on the surface. Substrates were first scrubbed with dilute Extran 300 detergent solution to remove organic residues before immersing in an ultrasonic bath of dilute Extran 300 for 20 min. Samples were rinsed in flowing deionized water for $5 \mathrm{~min}$ before being sonicated (Branson 5510) for $10 \mathrm{~min}$ each in successive baths of acetone and isopropanol. Next, the samples were dried with pressurized nitrogen before being exposed to a UV-ozone plasma for $10 \mathrm{~min}$. The organic small molecules (DFTAB and TAE) are dissolved in chlorobenzene with $10 \mathrm{mg} / \mathrm{ml}$ as concentration and stir overnight at $100^{\circ} \mathrm{C}$. This HTM solution was then spin cast at $2000 \mathrm{rpm}$ for 30 seconds, then annealed at $90^{\circ} \mathrm{C}$ on hot plate for 10 minutes. In the case of PEDOT:PSS, an aqueous solution (Clevios P VP AI 4083) was spin-cast at $4,000 \mathrm{rpm}$ onto the substrates and baked at $140^{\circ} \mathrm{C}$ for 15 minutes. Immediately after baking the substrates, the samples were then transferred into a dry nitrogen glovebox $\left(<3 \mathrm{ppm}_{2}\right)$ for active layer deposition. 
All solutions were prepared in the glovebox. Methyl-Ammonium Iodide was bought from DyeSol and Lead Iodide from Sigma Aldrich. $\mathrm{CH}_{3} \mathrm{NH}_{3} \mathrm{PbI}_{3}$ was synthesized by mixing $\mathrm{CH}_{3} \mathrm{NH}_{3} \mathrm{I}$ and lead iodide $\left(\mathrm{PbI}_{2}\right)$ at 1:1 $(0.8: 2.3 \mathrm{~g})$ equimolar ratio in $\gamma$-butyrolactone (Sigma Aldrich) (3.6 mL) and Dimethyl Sulfoxide (DMSO) (Sigma Aldrich) $(2.4 \mathrm{~mL})$ at $60{ }^{\circ} \mathrm{C}$, stirring for $12 \mathrm{~h}$. The PCBM (purchased from NanoC) was dissolved in chlorobenzene in a concentration of $10 \mathrm{mg} \mathrm{mL}^{-1}$ and the solutions were stirred overnight at $100{ }^{\circ} \mathrm{C}$.

The active layers were deposited by a one-step fast deposition-crystallization method. It is spin-cast from the solutions at $60^{\circ} \mathrm{C}$ at an optimized speed of $1,000 \mathrm{rpm}$ for 10 seconds followed by $5000 \mathrm{rpm}$ for 40 seconds during which (after 10 seconds) $200 \mu \mathrm{L}$ of chlorobenzene was quickly added to induce the fast crystallization. Subsequently, the film was annealed at $80{ }^{\circ} \mathrm{C}$ for 10 minutes before the deposition of PCBM by spin cast at 1500 rpm for 10 seconds. Next, the samples were placed in a thermal evaporator for evaporation of $100 \mathrm{~nm}$ of silver electrodes evaporated at $2 \AA \mathrm{s}^{-1}$, at a pressure less than $1 \times 10^{-6}$ Torr. Following electrode deposition, samples underwent $J-V$ testing.

\section{Device testing}

$J-V$ measurements of solar cells were performed in the glovebox with a Keithley 2400 source meter and an Oriel Sol3A Class AAA solar simulator calibrated to 1 sun, AM1.5 G, with a KG-5 silicon reference cell certified by Newport. The external quantum efficiency (EQE) measurements were performed at zero bias by illuminating the device with monochromatic light supplied from a Xenon arc lamp in combination with a dual-grating monochromator. The number of photons incident on the sample was calculated for each wavelength by using a silicon photodiode calibrated by NIST. 
WILEY-VCH
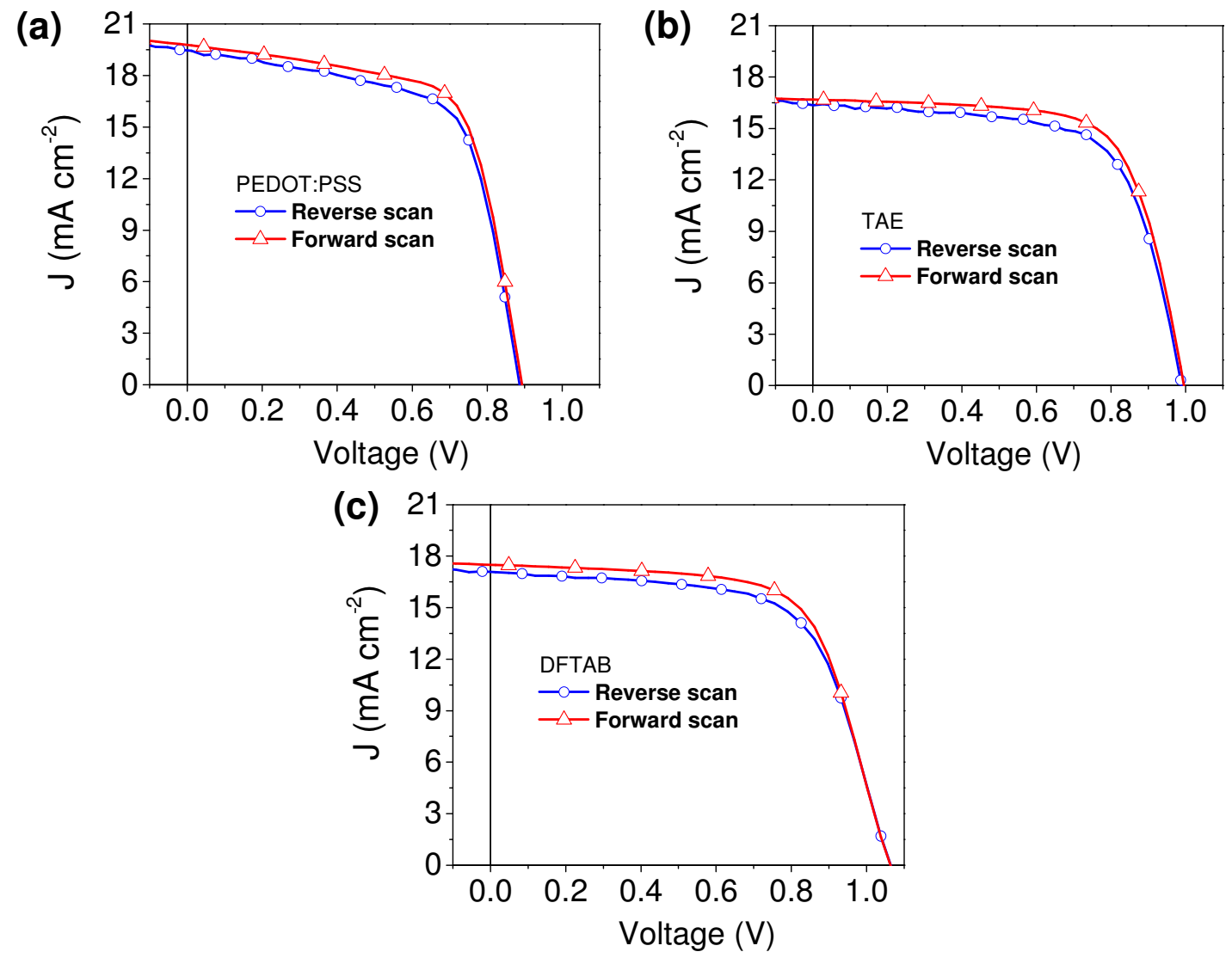

Figure S7. Forward and reverse IV scan for a) PEDOT:PSS, b)TAE and c) DFTBA. The decrease in PCE for reverse scans is $0.4 \%$ for PEDOT:PSS, $0.8 \%$ for DFTAB and $0.6 \%$ for TAE. 
WILEY-VCH

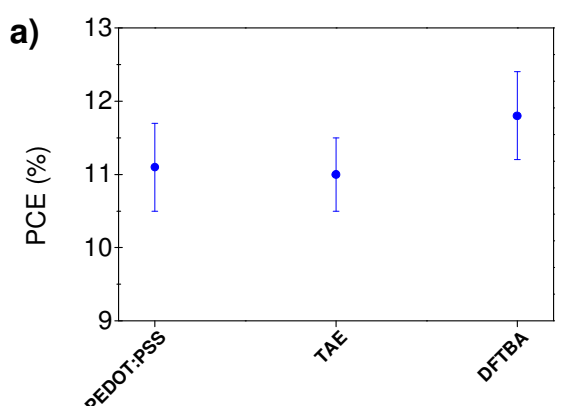

Hole Transport Material

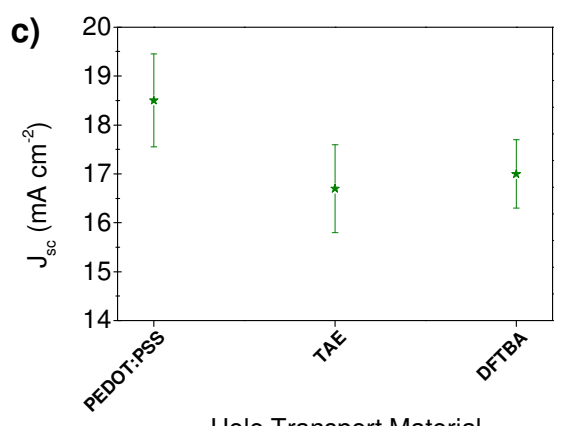

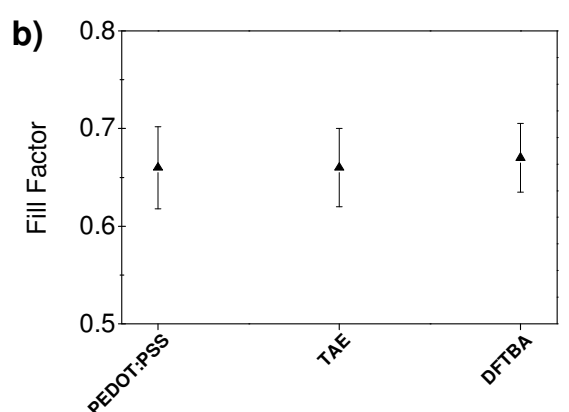

Hole Transport Material

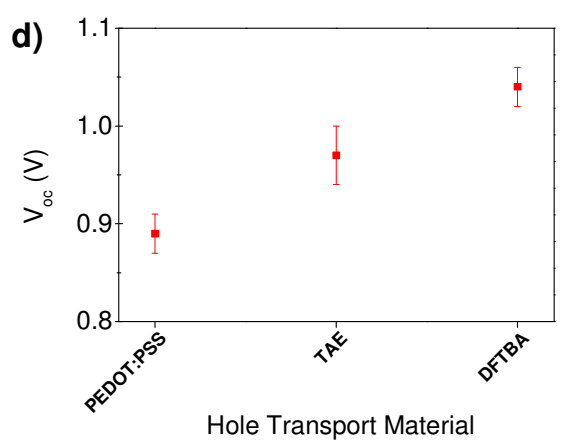

Figure S8. Photovoltaics parameter statistics for the different HTL for the optimized thicknesses. For each system, the markers denote the average values and error bars show the high and low values across 16 devices.
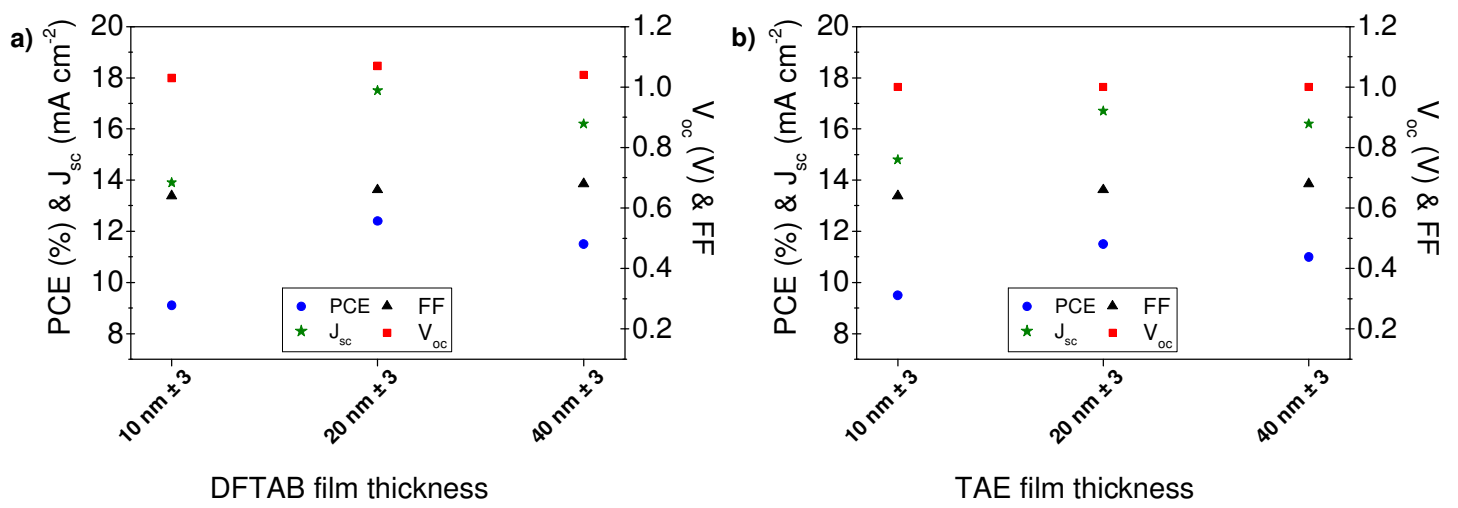

Figure S9. Photovoltaics parameter for different thicknesses. a) DFTAB, b) TAE. 
WILEY-VCH
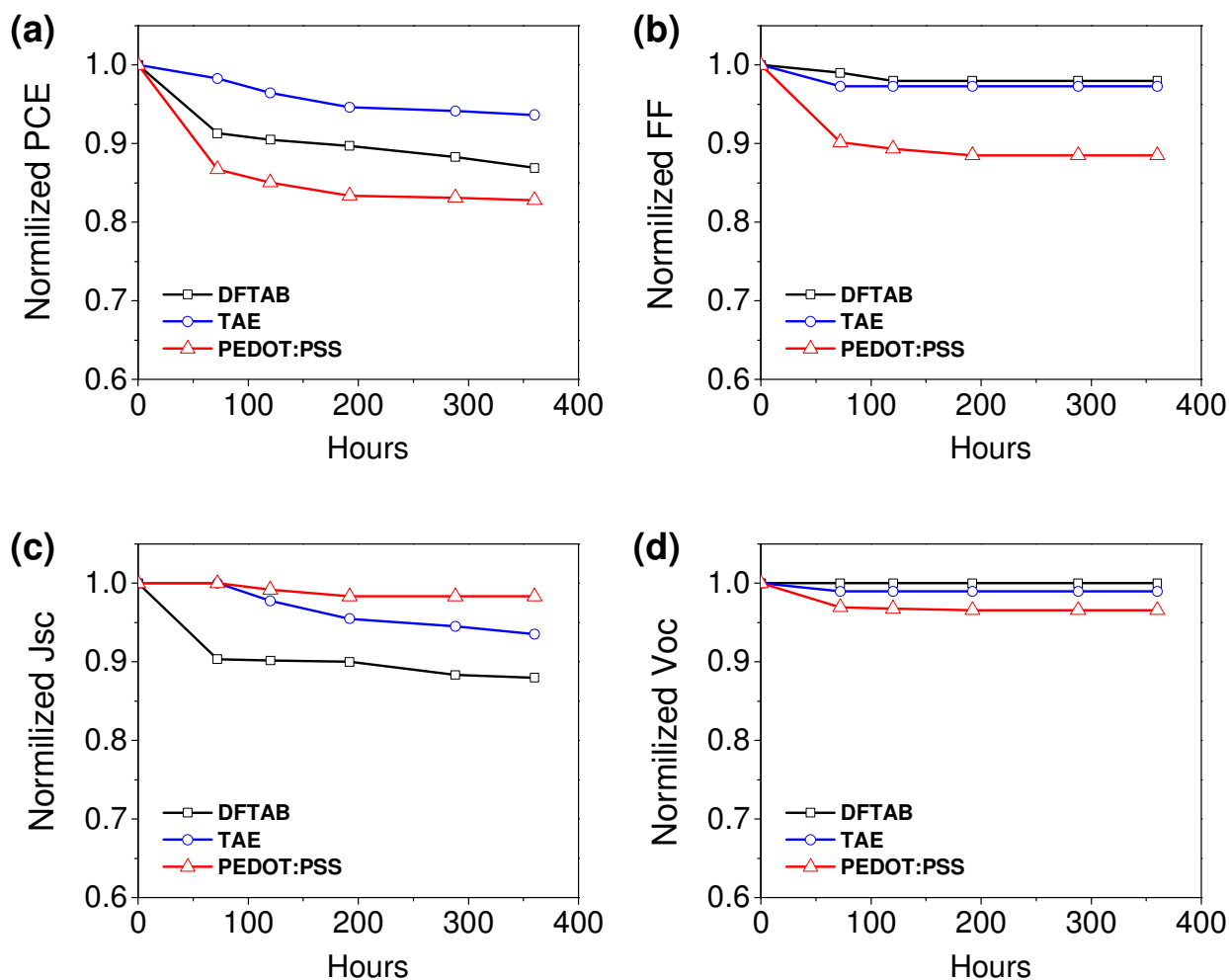

Figure S10. Variation of IV parameters for selected devices over 2 weeks of aging in an inert atmosphere without encapsulation.

\section{Films characterization}

The model AC-2 from Riken Instruments is a Photo-Electron Spectroscopy in Air (PESA) system was used to measure the ionization potential of the HTM. UV-Vis-IR absorption measurements were taken using a Cary 6000i from Varian equipped with an integrating sphere. The samples were positioned at the center of the sphere and tilted with $20^{\circ}$ angle respect to the incident light beam. This configuration allows most of the specular and diffused reflected and transmitted light to be integrated in the sphere and measured by the detector with minimal losses. Photoluminescence spectra were measured between $400 \mathrm{~nm}$ and $700 \mathrm{~nm}$ with step $1 \mathrm{~nm}$ on Horiba Fluoromax4 tool using Xenon lamp excitation at $350 \mathrm{~nm}$. Scanning electron microscopy (SEM) images were taken at $5 \mathrm{~V}$ accelerating voltage and beam aperture 
$30 \mu \mathrm{m}$, using a Zeiss Auriga microscope equipped with in-lens detector. For atomic force microscopy (AFM) measurements, AAC mode in Agilent 5500 SPM (Agilent Technologies) is used to get topography images on the surface simultaneously with phase images. AFM probes (FESP, Bruker) with the spring constant of $2.8 \mathrm{~N} / \mathrm{m}$ are employed for the measurement. Scanning speed is $0.8 \mathrm{~Hz}$.
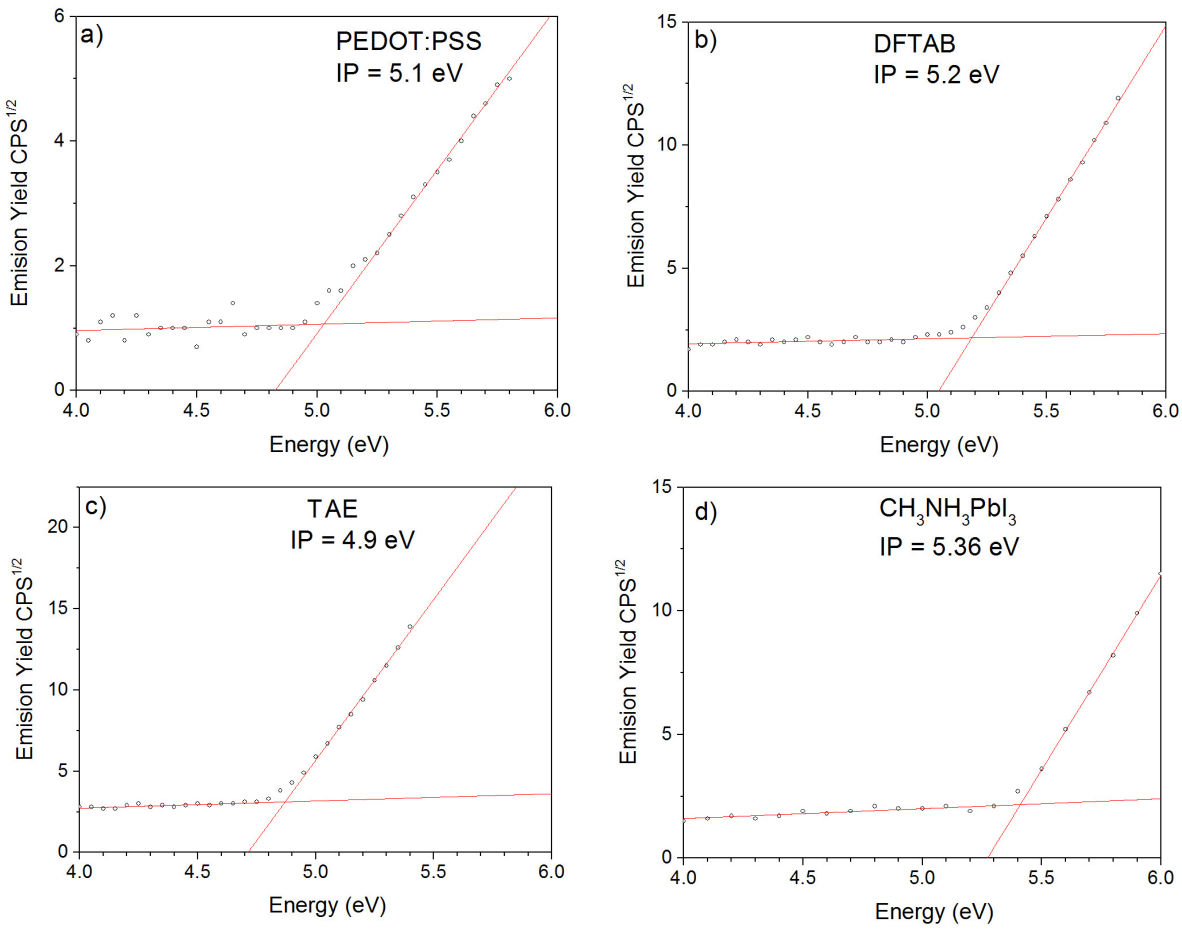

Figure S11. PESA mesurements for the different $\mathrm{HTMs}$ and for $\mathrm{CH}_{3} \mathrm{NH}_{3} \mathrm{PbI}_{3}$ 


\section{WILEY-VCH}
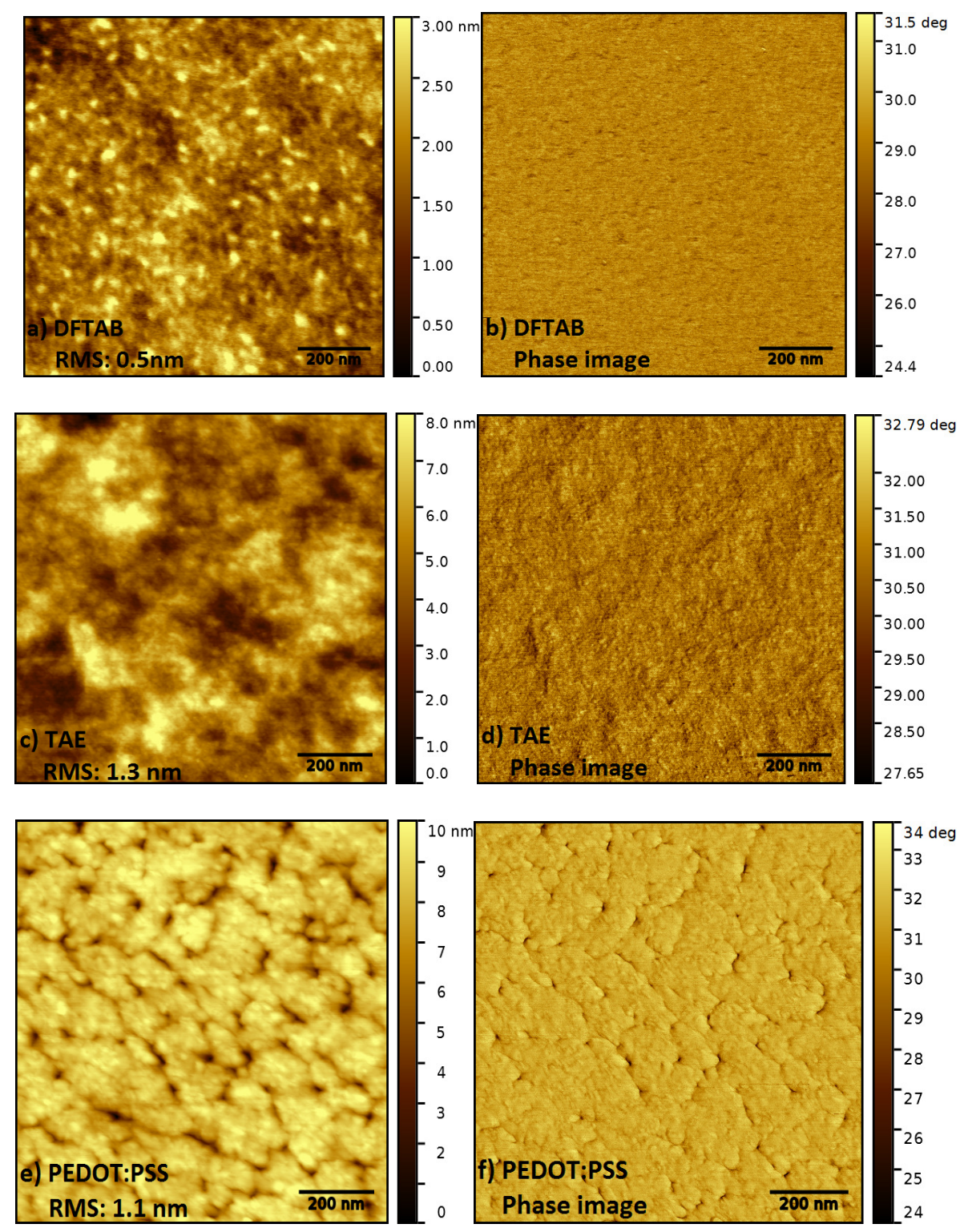

Figure S12. AFM images for the different HTL films. a), c) and e) are topography images. b), d) and f) are phase images.

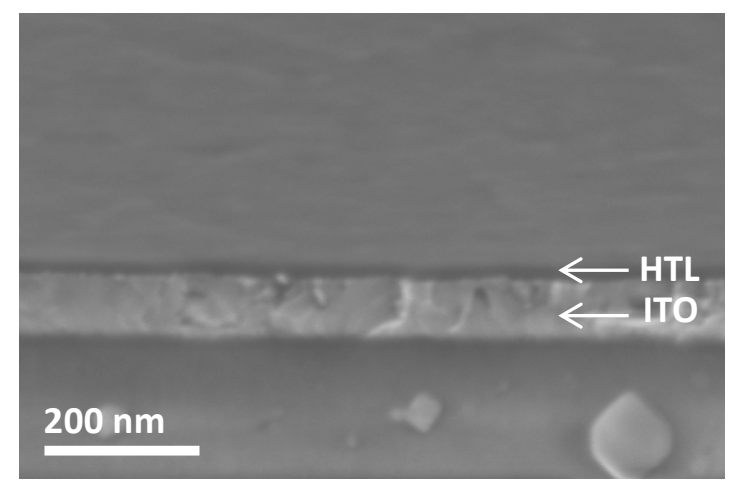

Figure S13. SEM cross-section (tilted $20^{\circ}$ from vertical axis) of DFTAB on ITO. 


\section{WILEY-VCH}

\section{SCLC measurements}

The hole-only devices with the structure glass/ITO/HTM/MoO $/ \mathrm{Ag}$ were prepared with the following procedure: HTM solutions were prepared in chlorobenzene with concentrations 20 $\mathrm{mg} / \mathrm{mL}$. The solutions were spin-cast at different speeds for $40 \mathrm{~s}$. Molybdenum oxide $(8 \mathrm{~nm})$ was thermally evaporated as an electron-blocking layer. Silver cathode $(80 \mathrm{~nm})$ were thermally evaporated under vacuum of $\sim 10^{-6}$ Torr, through a shadow mask defining an active area of $0.1 \mathrm{~cm}^{2}$. Hole mobilities were extracted by using a nonlinear least-squares fitting to the modified Mott-Gurney equation as shown below:

$$
J_{S C L C}=\frac{9}{8} \varepsilon_{0} \varepsilon_{r} \mu \frac{V_{\text {in }}^{2}}{L^{3}} e^{\left(\frac{0.89 \beta}{\sqrt{L}} \sqrt{V_{\text {in }}}\right)}
$$

where $\beta$ is the field activation factor, $\mathrm{L}$ speciment's thickness, $\mathrm{V}$ applied voltage, $\varepsilon_{0} \varepsilon$ are defined as electrical permittivity and $\mu$ is the hole zero field mobility.

Devices were tested over a large voltage range $(0-10 \mathrm{~V})$ to ensure that the current density is indeed space-charge limited and properly described by Equation (1). 


\section{WILEY-VCH}

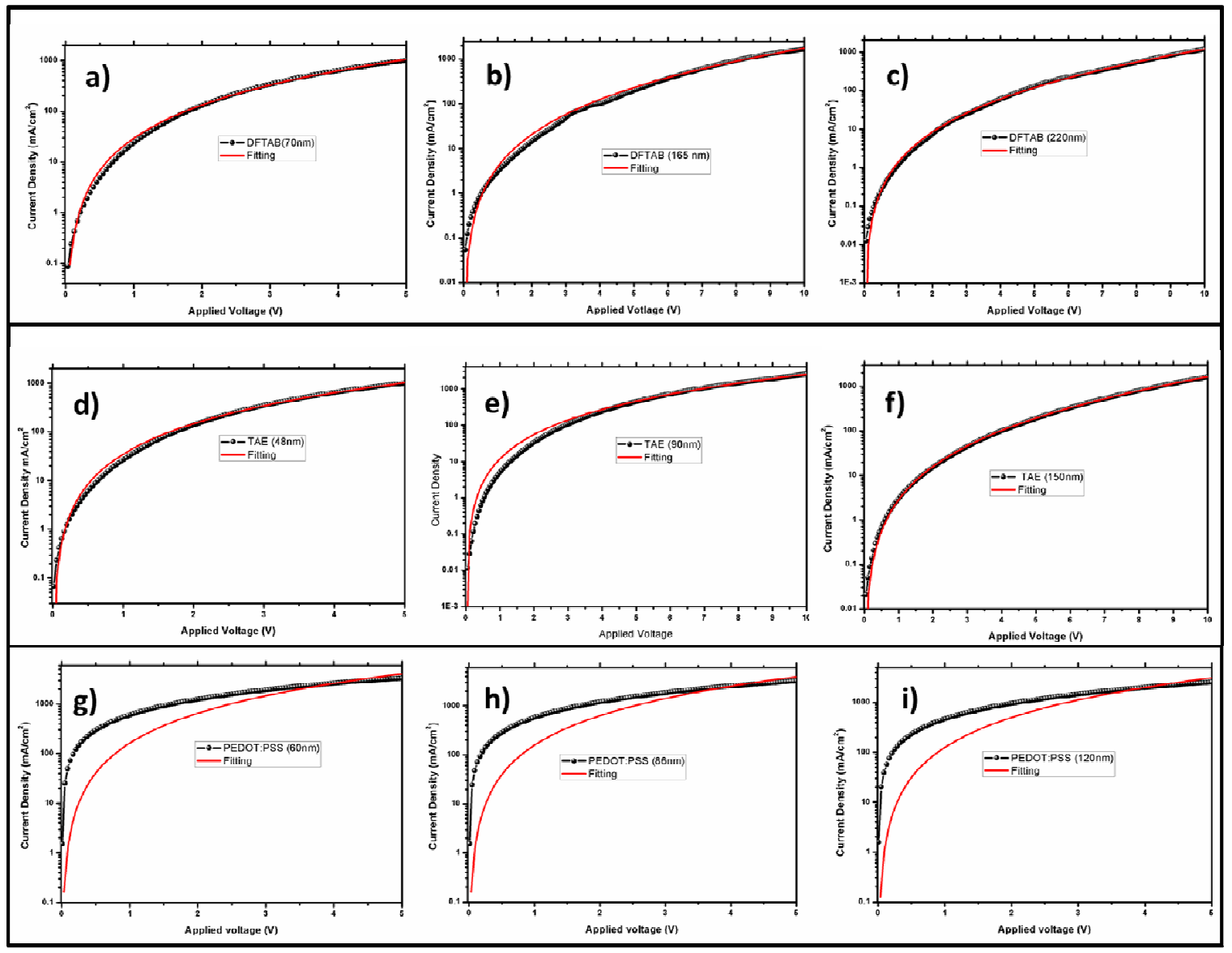

Figure S14. SCLC curves for the three different HTLs with three different thicknesses.

\begin{tabular}{c|c|c|c}
\hline \hline HTL & Thickness $(\mathbf{n m})$ & $\boldsymbol{\beta}\left(\mathbf{c m ~ \mathbf { V } ^ { - \mathbf { 1 } } ) ^ { \mathbf { 1 / 2 } }}\right.$ & $\boldsymbol{\mu}\left(\mathbf{c m}^{\mathbf{2}} \mathbf{V}^{\mathbf{- 1}} \mathbf{s}^{\mathbf{- 1}}\right)$ \\
\hline \hline DFTAB & 70 & $8.4 * 10^{-4}$ & $2.6 * 10^{-5}$ \\
\hline DFTAB & 165 & 0.0031 & $2.65 * 10^{-5}$ \\
\hline DFTAB & 220 & 0.0052 & $1.86 * 10^{-5}$ \\
\hline TAE & 48 & $3.16 * 10^{-4}$ & $1.14 * 10^{-5}$ \\
\hline TAE & 90 & 0.0011 & $2.06 * 10^{-5}$ \\
\hline TAE & 150 & 0.0035 & $1.47 * 10^{-5}$ \\
\hline PEDOT & 60 & 0 & $1.18 * 10^{-4}$ \\
\hline PEDOT & 86 & 0 & $3.3 * 10^{-4}$ \\
\hline PEDOT & 120 & 0 & $5.8 * 10^{-4}$ \\
\hline \hline
\end{tabular}

Table S1. SCLC results for the different HTLs with various thicknesses: field activation factor $\beta$ and hole mobility $\mu$. 